\title{
Sayo, zurrón y cayado: vestimenta $y$ atrezo en el teatro de Juan del Encina*
}

\author{
Sara SÁNCHEZ HERNÁNDEZ \\ Universidad de Salamanca \\ shara_ssh@usal.es
}

\section{RESUMEN}

El presente trabajo pretende estudiar la existencia de una configuración tópica del pastor teatral conformado a lo largo de las obras dramáticas de Juan del Encina. Para ello, analizo la vestimenta pastoril más frecuente en esta dramatis persona mediante el rastreo de las diversas didascalias icónicas implícitas que recorren los diálogos. Desde la convicción de la dualidad del texto dramático, propongo extraer los elementos del disfraz de pastor más recurrentes en Encina, de modo que se pueda mostrar la codificación convencional que este creó para sus personajes rústicos. El objetivo de este trabajo es, por tanto, analizar la figura del pastor sobre las tablas, es decir, estudio el texto espectacular, prestando especial atención a su apariencia física, su vestuario y atrezo típicos, siendo estos elementos realmente relevantes a ojos del espectador renacentista, puesto que el teatro no es solo palabra, sino también todos aquellos aspectos no verbales que forman parte del total del sistema de comunicación teatral. Asimismo, procuro mostrar la diversa funcionalidad del vestuario en sus representaciones dramáticas de finales del siglo XV y principios del XVI. El objetivo es anular la ya desgastada afirmación del primer teatro castellano como carente de teatralidad.

Palabras clave: Égloga dramática, Juan del Encina, Pastor rústico, Vestimenta, Teatralidad.

\begin{abstract}
This paper studies the existence of a topical configuration of the rustic shepherd in the dramatic works by Juan del Encina. To do this, I analyze the shepherd's costume most common in its dramatis persona by tracking the various implicit iconic stage directions preserved in the dramatic dialogues. Convinced of the duality of the dramatic text, I intend to extract the elements of the most recurring disguise in the shepherd of Encina to show the conventional codification created by the playwright for its rustic characters on stage. The purpose of this paper is, therefore, to analyze the shepherd on stage, that is, to study the performative text, paying particular attention to their physical appearance, their typical costumes, and props, because these elements were very important for the Renaissance viewers. I also propose to show the diverse functions of the costume in his dramatic representations of the late fifteenth and early sixteenth century. The purpose is to cancel the already worn assertion of the first Castilian theater as lacking of theatricality.
\end{abstract}

Keywords: Dramatic eclogue, Juan del Encina, Rustic shepherd, Clothing, Staging.

* Este trabajo es parte del estudio que me encuentro realizando actualmente en mi tesis doctoral, que en estos momentos se haya financiada por la Fundación Villalar-Castilla y León. 
Sumario: 1. Nociones teóricas, 2. El zurrón, 3. El cinto, 4. El cayado, 5. El sayo, el hato y el jubón, 6. «Ir en jubón»y «desnudarse» en escena, 7. Conclusiones.

\section{Nociones teóricas}

Es lugar común la afirmación de que el primer teatro renacentista no es más que un teatro primitivo, tan tosco y rudo como la mayor parte de sus protagonistas, carente de posibilidades teatrales y de perfección escénica ${ }^{1}$. Quizás esta afirmación proceda del formato impreso en el que se han trasmitido estos textos teatrales, como consecuencia de la falta de un modelo que recogiera las especificidades teatrales del género, por lo que emplean el formato cancioneril para su publicación. Aunque, si bien es cierto que existían ediciones teatrales de clásicos a finales del $\mathrm{XV}$, estas eran tratadas, al igual que ocurría con los textos clásicos, como «monumentos» dignos de comentario filológico y moral ${ }^{2}$. Por ello, es necesario abordar un análisis más teatral de los textos dramáticos, incidiendo en la dualidad del teatro como texto dramático y como texto literario que la crítica poco a poco va concediendo al género ${ }^{3}$.

Para el análisis, ante la falta de acotaciones escénicas tan frecuentemente señalada (lo que no anula la teatralidad de las piezas), me valgo de las numerosas didascalias implícitas de tipo icónico que recorren los diálogos teatrales de Juan del Enci$\mathrm{na}^{4}$. Asimismo, es necesario estudiar la vestimenta como signo y como uno de los distintos modos de transmisión de información del teatro ${ }^{5}$. Para ello me apoyo en la teoría semiótica que define el texto teatral como un macro-sign, una red de unidades semióticas que pertenecen a diferentes signos cooperativos, siendo uno de ellos

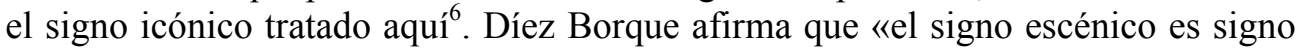
de signo» y «un signo por naturaleza equívoco que tiende hacia la univocidad». Para Profeti, el elemento icónico funciona como diferenciador del pastor frente a otros personajes. En este contexto, es interesante la definición de vestuario como «portador de signos» propuesta por Pavis, y la distinción entre «personaje visto» y

\footnotetext{
${ }^{1}$ Un ejemplo de este posicionamiento es H. López Morales (1968), pp. 120 y ss.

2 J. San José Lera (2013), p. 305.

${ }^{3}$ M. de Marinis (1978 y 1979), K. Elam (1980), sobre todo pp. 208-210; M. G. Profeti (1996); M. C. Bobes Naves (1997), pp. 32-33; y M. García-Bermejo Giner (2003), pp. 527548.

${ }^{4}$ A. M. Álvarez Pellitero (1999), p. 19. Empleo el análisis didascálico de A. Hermenegildo (2001).

${ }^{5}$ Un buen estudio sobre este aspecto es el ejemplar dedicado a El vestuario en el Teatro español del Siglo de Oro, M. de los Reyes Peña (2000).

${ }^{6}$ K. Elam (1980), pp. 9-31.
} 
«personaje leído», que responde a esa dualidad del texto teatral y muestra el paso del «estado virtual al estado icónico»?

Así, el presente trabajo se centra en la reconstrucción tópica del pastor de Encina mediante su vestimenta y sus diversas funciones en escena ${ }^{8}$. Para que el pastor sea reconocible en escena por el público, debe existir una serie de signos escénicos que ayuden a la codificación del hábito pastoril para su fácil identificación por los espectadores. Asimismo, sus rasgos icónicos deben funcionar como diferenciador con respecto a otros personajes de distinto ámbito social (cortesano) o de otra realidad (Amor o Venus). Por ello, dada la existencia de este personaje-tipo, es necesario llevar a cabo una relación de las prendas y atrezo más típicamente pastoril y de mayor frecuencia en las piezas ${ }^{9}$. De esta manera, se podrá apreciar cómo, de manera implícita, aparecen elementos tópicos del pastor, ya que son «personajes perfectamente reglamentados en su comportamiento escénico, en su lenguaje, en sus costumbres, en su axiología» ${ }^{10}$.

El disfraz típico pastoril, a grandes rasgos y con variaciones dependiendo de las necesidades dramatúrgicas de las églogas, se compone de sayo, zurrón y cayado, al que se pueden añadir otros complementos como el cinto, el hato o el jubón ${ }^{11}$.

\section{El zurrón}

Inicio este hato pastoril con el zurrón. Ya desde la primera égloga de Encina se presenta el zurrón en posesión del pastor Juan, quien guarda en él las «cien coplas» que procede a entregar a su señora la duquesa de Alba (vv. 73-81) ${ }^{12}$. Además de caracterizar al pastor como tal, este atrezo pastoril se emplea aquí en un juego entre Juan autor con su obra literaria y Juan pastor con su zurrón ${ }^{13}$.

En la Égloga representada la mesma noche de Antruejo, el zurrón vuelve a aparecer como portador de objetos. Además de elemento icónico, parece que aquí con-

${ }^{7}$ J. M. Díez Borque (1975), pp. 54-55; M. G. Profeti (1982), p. 309; P. Pavis (1983), s. v. personaje.

${ }^{8}$ Hay numerosos trabajos sobre varias perspectivas del pastor rústico: J. Brotherton (1975); F. Cazal, (1994); W. Crawford, (1911); F. López Estrada (1974); N. Salomon (1965). Para la confluencia de diversas fuentes en el pastor véase A. Hermenegildo (1995), p. 36 y J. del Encina (2008), pp. 35-43.

${ }^{9}$ Por falta de espacio dejo para otro trabajo el análisis minucioso de elementos esenciales como el tipo de telas y colores de los ropajes pastoriles y la puesta en relación del atuendo teatral con la representación pictórica de los pastores.

${ }^{10}$ A. Hermenegildo, (1995), p. 36.

${ }^{11}$ N. Salomon (1965), pp. 443 y 476.

12 Todos los ejemplos que aporto provienen de la edición de A. del Río, J. del Encina (2001), por lo que evito repetir la referencia bibliográfica en posteriores pasajes citados.

${ }^{13}$ Para las implicaciones del Encina actor véase J. del Encina (2001), p. XLVII, y J. M. Díez Borque (1990), p. 144. 
tribuye al desarrollo de la pieza. El pastor Pedruelo porta en su zurrón alimentos para celebrar el pantagruélico banquete que Beneito ya ha iniciado al comienzo de la obra. Ante la pregunta de «¿qué traes en el çurrón?», Pedruelo exhibe su «tarro de leche» (vv. 151-153). Deben de ser numerosos los alimentos que guarda o que guardaba el rústico en su zurrón porque exclama: «isi habrassen los çurrones!...» (v. 150), aspecto que no resulta nada descabellado si se tiene en cuenta que en escena se produce un banquete carnavalesco. Podría representarse sobre las tablas a Pedruelo cargando un enorme zurrón con todo lo que ha robado, según dejan entrever los otros pastores (vv. 155 y ss.); o al contrario, mostrar el zurrón vacío tras una gran comilona de la que solo ha sobrado el tarro de leche de cabra. Sea como sea, este apero pastoril posee una clara función cómica.

El zurrón presenta otro valor en la Égloga representada en requesta de unos amores, donde funciona como prenda amorosa que la pastora Pascuala dona al escudero por tornarse pastor. Así, dicho elemento debe aparecer en escena: «mi çurrón y mi cayado / tomad luego por estrena» (vv. 189-190), de manera que se contribuye al desarrollo de la trama ${ }^{14}$. Asimismo, el zurrón es uno de los dos complementos esenciales del disfraz rústico que el escudero va a vestir en escena tras convertirse a la «religión pastoril», hecho que conlleva trocar el atuendo ${ }^{15}$. De este modo, funciona también como icono de identificación social. No hay que olvidar tampoco la comicidad derivada del amor cortés parodiado, puesto que en esta pieza el regalo amoroso es algo tan rústico como un zurrón.

Otra funcionalidad que posee el zurrón de Encina aparece en la Égloga de Fileno, Zambardo y Cardonio. Es necesario que el representante que interpreta a Fileno porte un zurrón del que extrae sus pertenencias antes de quitarse la vida. Se trata de una escena de gran dramaticidad, que se ve ampliada con la dulce despedida de todas sus posesiones. Por ello, estas y el zurrón deben aparecer necesariamente sobre las tablas:

FILENO ¿Qué es lo que queda en aqueste çurrón?

No me ha de quedar salvo el cuchillo, pedernal terrena, yesca, eslavón, que vos en dos partes iréis, caramillo. ¿Queda otra cosa, si bien la cuchar?

${ }^{14}$ El zurrón también presenta esta función en la posterior obra pastoril el Colloquio de Selvagia, donde la protagonista le deja su zurrón al pastor dormido por mitigar la pena y este lo toma como signo amoroso. La pieza se cierra con el regalo del zurrón como dote de boda. De hecho, en el inventario de Oropesa, figuran «dos çurrones«, P. Cátedra García (2006), pp. 41-99 y 499 .

${ }^{15}$ La transformación de la identidad asociada al cambio de disfraz ha sido señalada por P. Pavis (1983), s.v. disfraz y M. García-Bermejo Giner, (2011), p. 89. Asimismo, M. Vázquez Melio (2012) ofrece un reciente estudio del tema en las églogas dramáticas de Encina. 
Çaticos de pan ten tú, venturado, pues el çurrón no me ha de quedar, ni vos en mal ora tanpoco, cayado (vv. 561-568).

Asimismo, el zurrón se halla presente en la Égloga de Cristino y Febea, donde aparece representado en la xilografía (ver Figura 1) y en la escena en la que Justino advierte a Cristino sobre la dificultad de hacerse ermitaño: «dexar çurrón y cayado / y de silvar el ganado / no podrás, yo te seguro» (vv. 98-100). Este accesorio puede marcarse verbalmente en escena como atrezo narrado. Sin embargo, parece que este complemento pastoril es necesario sobre las tablas para señalar el cambio de disfraz que se produce ante los ojos del espectador, al que le es suficiente con que Cristino troque un elemento propio del atavío ermitaño, como el balandrán, y adopte, en su lugar, el zurrón y el cayado. Su función es simbólica, ya que sirve para delinear las modificaciones de vestimenta con su aparejado cambio social, del mismo modo que el escudero cambia su indumentaria al tornarse pastor, como se ha analizado más arriba.

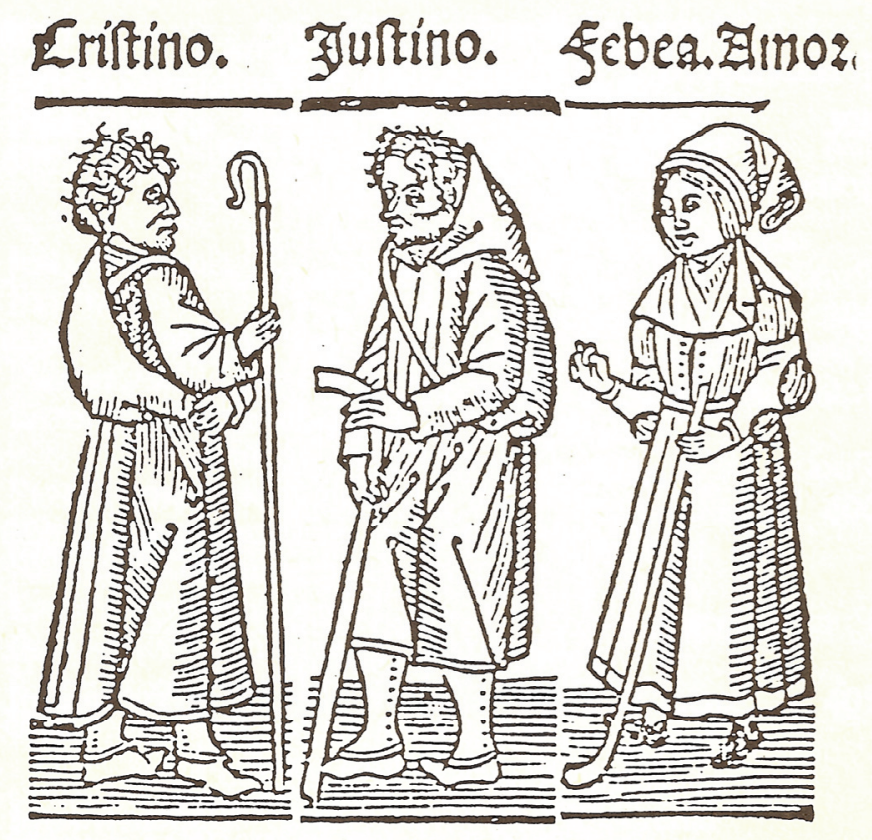

Figura 1. Xilografía de la suelta de la Égloga de Cristino y Febea ${ }^{16}$.

${ }^{16}$ J. del Encina (s. a.), fol. 1r. 


\section{El cinto}

Otro complemento que también da juego en las piezas teatrales de Encina es el cinto. En la Égloga de Fileno, Zambardo y Cardonio se menciona el «cinto que tiene tachones» de Zambardo (v. 150). Asimismo, Gil apuesta al juego del azar un «cinto de tachones» en la Égloga de Plácida y Vitoriano (v. 1134). En el primer caso, este complemento indica un contexto festivo, mientras que en el último, el cinto es un objeto visible en la escena entremesil que protagonizan los pastores Gil Cestero y Pascual.

Según el Diccionario de Autoridades, el tachón «se sobrepone en el vestido, u otras cosas semejantes por adorno, para hacerlas más vistosas, y sobresalientes (...). Se llama assimismo la tachuela grande, regularmente dorada, o plateada» ${ }^{17}$. Así pues, bien como atrezo verbal, bien con presencia escénica, el cinto resalta por su colorido e indica esa vistosidad del vestuario para ocasiones especiales. Los pastores del entremés incluso lo consideran de más valor que la «mejor alhaja» (v. 113132). Carmen Bernis también recoge que el cinto se hacía de cuero o de una especie de cinta llamada tejillo, que podía forrarse de tela y que además llevaba meta $1^{18}$. Por la información que aporta, la prenda hecha de tejillo parece más apta para nobles, mientras que la gente popular emplea una versión más simple del cinto, fabricado con cuero, que podrían reservar para celebraciones importantes. También su coetáneo Lucas Fernández lo aprovecha para caracterizar al pastor orgulloso Bonifacio en la Égloga o farsa del Nascimiento de nuestro Redemptor Jesucristo:

Tengo jubón de frolete, sayo de cestrepicote, tengo cinto y cauiñete, caperuça de ferrete, de sayal vn buen capote, fedegosa y dos çurrones, y cayado, llugas, pañicos, calçones, d'estopa dos camisones. ¡So gran pastor de ganado! ${ }^{19}$

\footnotetext{
${ }^{17}$ El cinto con tachones aparece en la copla VI de Mingo Revulgo: «y de quanto ha levado, / non le veo que ha medrado / otros hatos nin jubones, / salvo un cinto con tachones / de que anda rodeado». Las coplas de Mingo Revulgo (1996), p. 86. Otra versión del cinto aparece también en el villancico de Encina «Daca, bailemos, carillo», donde parece que el pastor enamorado de Bartola quiere acicalarse para conquistar a la pastora en el baile: «pues también me has de prestar / el tu jubón colorado, / y el cinto claveteado / para salir a bailar, / porque no quiero llevar / otra capa ni capillo», J. Encina (1996), p. 742, vv. 57-62.

${ }^{18}$ C. Bernis Madrazo, (1979), p. 79.

${ }^{19}$ L. Fernández (1976), p. 167, vv. 51-60.
} 
El cinto, junto al resto del hato pastoril que enumera el pastor, parece un elemento de gran calidad según la apreciación del propio rústico. Este atrezo pastoril evoluciona en el tiempo, llegando a ser un elemento específico del bobo áureo ${ }^{20}$.

\section{El cayado}

El cayado es otro componente básico en el atrezo del pastor ${ }^{21}$. Aparte de su ya aludida función identificativa del pastor por parte del público, el cayado presenta otras funciones teatrales en escena. La pastora Pascuala lo menciona en la Égloga representada en requesta de unos amores:

Hete, viene un escudero.

Vea que eres pastorcillo:

sacude tu caramillo, tu hondijo y tu cayado; haz que aballas el ganado, silva, hurria, da gritillo (vv. 43-48) $)^{22}$.

Se trata de un sistema del dramaturgo para señalar la condición social del personaje sobre las tablas, como ya se ha analizando en otros casos. Tanto el escudero como el auditorio se cercioran de que Mingo es un pastor. Asimismo, el cayado es la prenda amorosa que Pascuala entrega al recién transformado pastor Gil, junto con el zurrón citado.

El cayado es, además, figura que crea ocasiones de comicidad, ya que sirve para golpear. En el villancico final de esta pieza se emplea para castigar al ganado:
Queda, queda acá el vezado: helo, va por aquel cerro.
Arremete con el perro y arrójale tu cayado, que anda todo desmandado (vv. 219-223).

Esos golpes tan caracterizadores del pastor rústico del Quinientos, mediante los que se logra gran comicidad escénica, se consiguen gracias al cayado. Asimismo, si se tiene en cuenta la definición de Covarrubias según la cual el cayado es «el báculo de pastor, con que encamina, y rige el ganado, que por la parte de arriba está torcido

\footnotetext{
${ }^{20}$ En el hato de Oropesa aparece «un çinto de bobo de cuero blanco», P. Cátedra García (2006), p. 503.

${ }^{21}$ El pastor junto al cayado está en los orígenes de la literatura pastoril como los Idilios de Teócrito (1963), pp. 97-98; así como en la tradición clásica de las Bucólicas de Virgilio. Véase el trabajo de F. López Estrada (1974).

${ }^{22}$ Es importante la mención del instrumento musical como elemento icónico, así como el hondijo, pero por cuestiones de espacio, dejo para otra ocasión su análisis.
} 
y tiene un gancho para asir con él, el pie de la res», podría interpretarse que «arrojar el cayado» sería acercar el cayado por su parte curva para asir al ganado desmandado (ver Figura 1$)^{23}$.

En la Égloga de Plácida y Vitoriano el bastón se emplea como instrumento esencial para el juego del cayado o del azar como medio de entretenimiento (vv. 1124-1175). En la misma pieza también aparece el cayado como soporte para el tullido Pascual (vv. 999-1024), otra de las funciones esenciales del báculo de pastor: «de otro género de cayados, o báculos usan los viejos para sustentarse por la flaqueza que sienten en los pies», situación que también induce a risa cortesana ${ }^{24}$. Además, todo este pasaje entremesil cumple una función cómica esencial, ya que marca el contraste entre el mundo de los urbanos (Vitoriano, Suplicio y Plácida) y los pastores. Dado que lo pastoril es accesorio en esta égloga, el papel esencial de los rústicos es crear comicidad en un punto de la acción donde prima lo trágico.

\section{El sayo, el hato y el jubón}

Uno de los ropajes pastoriles que más connotaciones posee en el teatro de Encina es el sayo. Según el Diccionario de Autoridades el sayo es «casaca hueca, larga, y sin botones, que regularmente suele usar la gente del campo, u de las aldeas». Para Covarrubias es «vestidura, que recoge y abriga el cuerpo, y sobre ella se pone la capa para salir fuera de casa ${ }^{25}$. En ambas definiciones se marca el carácter rústico y práctico de la prenda. Esta prenda aparece en la primera Égloga representada en la noche de Natividad en la que Juan afirma que:
Aunque agora yo no trayo
sino hato de pastores,
dexa tú venir el mayo
y verás si saco un sayo
que relumbren sus colores (vv. 86-90).

Como se puede apreciar, en estos versos existe un contraste entre dos tipos de atuendo. Por un lado, estaría la vestimenta típica del personaje rural para las tareas ganaderas. Es el «hato de pastores», que está confeccionado de paño pardo, el color de la lana sin teñir. Covarrubias define pardo como el «color que es el propio que la oveja, o el carnero tiene, y le labran y adereçan, haziendo paños del sin teñirle (...). El vestido pardo es de gente humilde» ${ }^{26}$. Por lo tanto, el hato es el ropaje pardo que

\footnotetext{
${ }^{23}$ S. de Covarrubias Orozco (1611), s. v. cayado.

${ }^{24}$ S. de Covarrubias Orozco (1611), s. v. cayado.

${ }^{25}$ Real Academia Española (1739) y S. de Covarrubias Orozco (1611), s. v. sayo, respectivamente.

${ }^{26}$ S. de Covarrubias Orozco (1611), s. v. pardo. El Diccionario del castellano tradicional se indica que en Castilla y León «se utiliza el término, con sentido peyorativo, para significar
} 
emplean los aldeanos y posee un carácter más utilitario que el traje cortesano. Por otro lado, el sayo con colores «relumbrantes» se reserva para ocasiones especiales, como se vio en el caso del cinto ${ }^{27}$.

En la Égloga de Fileno, Zambardo y Cardonio también se menciona un «sayo ametalado» que se relaciona con ocasiones festivas como el mayo (vv. 146-148). Según el Diccionario de Autoridades, el ametalado es «cosa perteneciente a metal, que o tiene parte de metal, o es semejante en el color al azófar comúnmente llamado metal». Se trata de un sayo para fiesta o de mayor categoría, ya que presenta unos adornos que simulan el metal, al modo de la moda cortesana de la época, frente al color pardo para gente pobre ${ }^{28}$. En esta pieza sirve también para contrastar lo material, representado por Zambardo, frente a lo sentimental, encarnado por Fileno.

Aunque no hay que olvidar que el pastor se muestra orgulloso sus prendas de vestir festivas, hay que destacar que este tipo de sayo no deja de ser rústico, debido al tipo social que lo emplea ${ }^{29}$. Como recoge el Diccionario del castellano tradicional, el sayal es «clase de tela muy basta hecha de lana y usada para hacer ropa para el campo ${ }^{30}$. Por tanto, pienso que los pastores las consideran piezas de distinta calidad y reservadas para fines disímiles, por lo menos el pastor Juan equipara su

la indumentaria descuidada o poco elegante que alguien lleva», C. Hernández Alonso (2001), s. v. pardo.

${ }^{27}$ Que la ropa con colorido se halla destinada para gentes de buen vestir o para demostrar un mayor nivel frente a los que visten de pardo, lo demuestra un villancico del mismo Encina «Una amiga tengo, hermano»: «no se viste mi querida / sino paños de color; / de joyas de gran valor / siempre está muy bien guarnida», J. del Encina (1996), p. 745, vv. 81-84. Recoge sayos coloridos el hato de Gaspar de Oropesa, P. Cátedra García (2006), pp. 499-500. También el villancico pastoril de Urrea «Qué aprovecha, Pascualejo», un pastor enamorado describe para este a la zagala que le trae encendido de amores: «salió a la plaça una fiesta / vestida de mil colores», P. M. de Urrea (2012), vol. II, pp. 745-47, vv. 18-19. También en Otra égloga suya adonde se introduzen tres pastores del mismo Urrea, parece que el pastor Pascual pretende cambiarse de ropa para ir a la fiesta: «pero andad, yd a la fiesta, / que yo quiero yr all aldea; / vestirm'é por que se vea / si mi persona es dispuesta», Urrea (2012), vol. III pp. 957-958, vv. 337-340.

${ }^{28}$ Real Academia Española (1726-1739). Un tipo de adorno para ocasiones más especiales lo muestra el hato de Oropesa, que incluye «dos sayos, uno berde y otro naranjado de tafetán con sus randas de plata falsa» y «otro sayo que no está acabado de tafetán de colores con randas de plata falsa», P. Cátedra García (2006), p. 500. Esa mención a la plata falsa estaría en consonancia con el intento de los villanos por parecerse a los cortesanos al vestir de gala.

${ }^{29}$ F. Cazal (1994), p. 11. L. Puerto Moro (2011), p. 302, destaca este misma prenda como identificadora social e inducción a burla de un personaje rústico de La Celestina como es Sosia.

${ }^{30}$ C. Hernández Alonso (2001), s. v. sayal. 
futura producción literaria con un sayo de colores, aunque, en cualquier caso, seguirían siendo rústicos a ojos de los cortesanos ${ }^{31}$.

En la Égloga de Mingo, Gil y Pascuala, vuelve a aparecer este atavío en oposición a otro tipo de sayo:

$\begin{array}{ll}\text { GIL } & \begin{array}{l}\text { (...) Toma, toma este mi sayo, } \\ \text { que otro tengo que allí trayo. }\end{array} \\ \text { MINGO } & \begin{array}{l}\text { No lo quiero, compañón, } \\ \text { que tiene muy gran mangón. }\end{array} \\ \text { GIL } & \begin{array}{l}\text { Calla, calla, qu'es al talle. } \\ \text { Dome a Dios que no me halle, } \\ \text { pareceré frailejón (vv. 418-424). }\end{array}\end{array}$

Parece que hay una jerarquización social de los sayos. Mientras que Gil, como buen escudero, gusta de sayos de «gran mangón» y «al talle», propios de la moda cortesana de fines del siglo XV, Mingo los prefiere con manga estrecha y más hol$\operatorname{gados}^{32}$. Estos dos modos de vestir contrastarían fuertemente en escena. Además, Encina se vale del juego del disfraz para conferir teatralidad. Por tanto, la caracterización física del pastor en escena está basada en una realidad social empleada como aspecto diferenciador del personaje de extracción rural.

Mientras que en la égloga primera era un «hato de pastores» lo que llevaba Juan, en la Égloga de Mingo, Gil y Pascuala, el primero de ellos nombra sus «hatos domingueros» (v. 306). El siguiente pasaje muestra el contraste entre la vestimenta tópica del pastor y el cambio de ropajes, donde aparece también el hato dominguero:

${ }^{31}$ El mismo Encina en «A un su amigo, gran poeta», emplea la ropa con valor simbólico para establecer contrastes: «A modo de cortesanos / lo emendad, no vaya assí, / porque no burlen de mí / los que fueren palancianos; / y aun también los aldeanos / (...) De mi grossero sayal / y vuestro fino brocado, / hecho un sayo de ametalado, / ved si parecerá mal; / mas, pues que grossero y tal / de mi lavor le queréis, / bordadle de buen metal, / que, por más que lo emendéis, / aun le quedará señal»; J. del Encina (1996), p. 333, vv. 37-41, 46-54. El brocado, por otro lado, era una «tela de seda entretejida con oro o plata, de modo que el metal forme en la cara superior flores o dibujos briscados», Real Academia Española (2001), s. v. brocado. Más adelante en el tiempo, Fray Luis criticará la obsesión de llevar todo tipo de telas brocadas para ir a la moda y recargados en La perfecta casada, L. de León (1992), pp. 97-98.

${ }^{32} \mathrm{C}$. Bernis Madrazo recoge la diversidad de sayos en tamaños, longitud, jerarquía y corte de finales del siglo XV (1979), p. 15. Durante el siglo XVI hay una especialización del sayo, P. M. Cátedra García (2006), p. 499. La vestimenta a la moda también se aprecia en el villancico de Encina «Una amiga tengo, hermano», donde, para hacer valer a la pastora, se dice de ella que «saya plegada y fruncida / a fuer de la serranía» J. del Encina (1996), p. 745 , vv. 85-86. 


$\begin{array}{ll}\text { GIL } & \text { Cata, cata, cata Mingo. } \\ & \text { ¿Eres tú quien estos días? } \\ & \text { ¿Cómo nunca te vestías } \\ & \text { esse hato algún domingo? } \\ \text { MINGO } & \text { Nuevamente me lo cingo. } \\ \text { GIL } & \text { ¿Qué buen capuz colorado! } \\ \text { MINGO } & \text { Y el jubón es bien chapado (vv. 409-415). }\end{array}$

Este hato dominguero, en concreto el «sayo dominguero» es definido por Covarrubias como «el que se viste solamente en las fiestas» $»^{33}$. Correas recoge un proverbio sobre esta prenda de vestir «Guarda el sayo para Mayo» y la explicación que da es: «que conserves los vestidos buenos para los tiempos y ocasiones en que te has de honrar con ellos, porque en Mayo es tiempo de muchas fiestas, en que luce la gala, y en invierno se pasa con vestidos que abriguen sin ella». Añade en otra ocasión que el color bermejo y colorado «significa alegría», por lo que encaja bien en este contexto festivo ${ }^{34}$. Se trata de nuevo de una amalgama de funciones de esta indumentaria. En primer lugar, marca un cambio de condición social producida en escena y, en consecuencia, hace que se desarrolle la trama teatral. En segundo lugar, se trata de crear comicidad ante el público al ver que un pastor con greñas en guisa de cortesano realiza comentarios jocosos en relación a sus nuevas vestiduras.

En Fileno, Zambardo y Cardonio se nombra ese atuendo pastoril más acorde para celebraciones como el mayo. Antes se mencionó el sayo ametalado, ahora es el jubón «vayo» (v. 149) que, según el Diccionario de Autoridades, es «color dorado bajo, que tira a blanco» ${ }^{35}$. Si el sayo contiene tonos ametalados, el jubón los posee dorados, pero ambos colores son más adecuados para un festejo que para vestir de cotidiano. Además, el conjunto formado por jubón y calzones no era el dominante en el traje rural, pues «los villanos preferían vestir sobre la camisa, en lugar de ju-

${ }^{33}$ Como ya dejó entrever de M. de Lope, este ropaje no debe confundirse con ropa de domingo, M. de Lope (1987), p. 140. Tanto el hato como el jubón aparecen de nuevo en Mingo Revulgo como sinónimo de riqueza: «que es del tu sayo de blao / non lo vjstes en domingo / do es el tu jubon bermejo», Las coplas de Mingo Revulgo, 1986, copla I, p. 85, y Hernando del Pulgar le da el significado de «vestirlo en la fiesta», R. de Cota (1787), fol. 2. En la Égloga trobada por don Pedro Manuel de Urrea el pastor Galeyo hace relación de sus posesiones para conquistar a su enamorada Antona: «y más tengo en mi cabaña, / donde el hato se rebaña: / queso que vale dineros, y vestidos domingueros / por vaylar quando se taña», P. M. de Urrea (2012), vol. III, pp. 964-985, vv. 206-210.

${ }^{34}$ G. Correas (1906), p. 301 y 586.

${ }^{35}$ Es interesante la apreciación de C. Bernis Madrazo sobre los jubones forrados con borra o algodón que «permitían aparentar una robustez que no era real» (1979), p. 12. En Cristino y Febea, este es «el más huerte del lugar»(v. 69), en la Égloga o farsa de L. Fernández (1976) Bonifacio lo lleva y dice ser muy fuerte (vv. 25 y 51). ¿Podrían valerse los actores de este tipo de prenda crear efectos cómicos en escena? 
bón, un sayo». Asimismo, el jubón quedaba cubierto por otras prendas excepto las mangas y el cuello. Por ello, era costumbre emplear en ellas una tela más rica y de distinto color que la del cuerpo, de ahí que Fileno haga referencias a las «mangas del tu jubón vayo» (v. 149) ${ }^{36}$.

\section{6. «Ir en jubón» y «desnudarse» en escena}

Finalizo este recorrido por la indumentaria pastoril con una breve mención de dos expresiones relacionadas con el modo de vestir en escena. La expresión «ir en jubón» aparece en la Égloga de Mingo, Gil y Pascuala. Al escudero le extraña que Mingo vaya en jubón: «¿Y tú vienes en jubón? / Toma, toma este mi sayo, / que otro tengo que allí trayo» (vv. 417-19). La referencia «venir en jubón» parece que equivale a la expresión, hoy también usada, «vestir a cuerpo». Sin embargo, a fines de la Edad Media, «de un hombre en calzas y jubón se decía que estaba desnudo. Para presentarse en público tenía que llevar otra prenda encima, cuando menos» ${ }^{37}$. De ahí que Gil le ofrezca a Mingo uno de los sayos que posee para vestírselo encima. ¿Sería esta una situación cómica? Imaginemos que Mingo, no acostumbrado a esas modas cortesanas, aparece con esta prenda en escena. A ojos del público estaría semidesnudo, lo que causaría grandes risas y burlas, y más si imaginamos que Gil se apresura a taparle con uno de sus sayos intentando que el público no lo vea en esa guisa y realizando ademanes exagerados.

De igual modo, en la Égloga de Plácida y Vitoriano aparece algo relacionado con el concepto de desnudarse sobre las tablas. Ocurre en la escena en la que la dama decide llevar a cabo su suicidio. Plácida se despoja de sus prendas de vestir: «para más presto matarme, / muy bien será desnudarme / y quitarme los vestidos / que me estorvan» (vv. 1290-93). De nuevo, hay que entender que nuestra expresión actual «desnudarse» no equivale a lo que Plácida debe realizar en escena. Bastaría con que se deshiciera de parte de su vestimenta, como la saya o el capote para poder clavarse mejor el cuchillo.

\section{Conclusiones}

En resumen, vista la nómina de vestimenta y atrezo típicamente pastoriles que recorren el teatro de Juan del Encina, parece que se puede reconstruir lo que pudo ser el disfraz tópico del pastor posiblemente empleado en las representaciones de los albores del teatro castellano que, por otro lado, disponía de los suficientes y bien explotados recursos teatrales ${ }^{38}$. A pesar de que no se mencionan todos los elementos

\footnotetext{
${ }^{36}$ C. Bernis Madrazo (1979), p. 12.

${ }^{37}$ C. Bernis Madrazo (1979), pp. 13-14.

${ }^{38}$ La existencia de un personaje-tipo lo pone de manifiesto Puerto Moro cuando concluye que en La Celestina existe «un camino insuficientemente recorrido: el que permite conectar
} 
rústicos en cada pieza, el hato de pastores, junto con el jubón, el cinto, el sayo, el zurrón y el cayado contribuyen a dar vida a este personaje rústico y a añadir potencialidad teatral a las obras dramáticas. Asimismo, se puede extraer el uso escénico de este disfraz que luego evolucionará con el gracioso y el bobo del teatro áureo para construir teatralidad. En fin, el teatro de Juan del Encina conserva la esencia de lo que debió de ser el espectáculo teatral en las tablas de finales del siglo XV y del naciente siglo XVI.

\section{OBRAS CITADAS}

Álvarez Pellitero, Ana María: «Tradición y modernidad en el teatro de Juan del Encina», en Humanismo y literatura en tiempos de Juan del Encina, Salamanca, Universidad de Salamanca, 1999, pp. 15-26.

BERNIS MADRAZO, Carmen: Trajes y modas en la España de los Reyes Católicos. II, Los hombres, Madrid, Instituto Diego Velázquez, 1979.

Bobes Naves, M ${ }^{a}$ del Carmen: Semiología de la obra dramática, Madrid, Arco Libros, 1997.

BROTHERTON, John: The «Pastor-bobo» in the Spanish Theatre before the Time of Lope de Vega, Londres, Támesis, 1975.

CÁTEDRA GARCÍA, Pedro: Tres coloquios pastoriles» de Juan de Vergara y Lope de Rueda (Valencia, 1567), San Millán de la Cogolla, Cilengua, 2006.

CAZAL, Françoise: «Del pastor bobo al gracioso: el pastor de Garci Sánchez de Badajoz», Criticón, 60 (1994), pp. 7-18.

Coplas de Mingo Revulgo, Las, Vivana Brodey (ed.), Madison, The Spanish Seminary of Medieval Studies, 1996.

CORREAS, Gonzalo: Vocabulario de refranes y frases proverbiales y otras fórmulas comunes de la lengua castellana, Madrid, Establecimiento Tipográfico de Jaime Ratés, 1906.

CotA, Rodrigo de: Coplas de Mingo Revulgo compuestas por Rodrigo de Cota, glosadas por Hernando del Pulgar, Madrid, Imprenta de D. Antonio de Sancha, 1787.

COVARRUBias OROzCO, Sebastián de: Tesoro de la lengua castellana o española, Madrid, Luis Sánchez, 1611. Biblioteca de la Universidad de Sevilla, A 253/315. CRAWFORD, Wickersham: «The pastor and bobo in the Spanish religious drama of the sixteenth century», Romanic Review, 2 (1911), pp. 376-401.

una parte considerable de sus personajes con la tipología cómica tradicional de la época», L. Puerto Moro (2011), p. 311. 
DíEz BORQUE, José María: «Aproximación semiológica a la "escena" del teatro del Siglo de Oro español», en Semiología del teatro, Barcelona, Editorial Planeta, 1975, pp. 49-92.

: «La obra de Juan del Enzina: una poética de la modernidad de lo rústico pastoril», en Los géneros dramáticos en el siglo XVI (El teatro hasta de Vega), Taurus, Madrid, 1990, pp. 125-148.

ELAM, Keir: The semiotics of theatre and drama, London, Mouton, 1980.

ENCINA, Juan del: Égloga nuevamente trobada por Juan del Enzina, s.l., s.i., s.a., Santander, Biblioteca de Menéndez Pelayo, R-III-A (595).

: Obra completa, Miguel Ángel Pérez Priego (ed.), Madrid, Fundación José Antonio de Castro, 1996.

: Teatro, Alberto del Río (ed.), Barcelona, Crítica 2001.

: Teatro completo, Miguel Ángel Pérez Priego (ed.), Madrid, Cátedra, 2008.

FERNÁNDEZ, Lucas: Farsas y églogas, $\mathrm{M}^{\mathrm{a}}$ Josefa Canellada (ed.), Madrid, Castalia, 1976.

GARCÍA-BERMEJO GINER, Miguel: .«Transmisión y recepción de la obra teatral en el siglo XVI» en Historia del teatro español, Madrid, Gredos, 2003, pp. 527548.

: «Disfraz, máscara e identidad en el primer teatro prelopesco (de Encina a Torres Naharro)», en Máscaras y juegos de identidad en el teatro español del Siglo de Oro, Madrid, Visor Libros, 2011, pp. 75-90

Hermenegildo, Alfredo: Los juegos dramáticos de la locura festiva. Pastores, simples, bobos y graciosos del teatro clásico español, Palma de Mallorca, José de Olateña editor, 1995.

: Teatro de palabras: didascalias en la escena española del siglo XVI, Lleida, Edicions de la Universitat de Lleida, 2001.

HERNÁNDEZ AlONSO, César (coord.): Diccionario del castellano tradicional, Valladolid, Ámbito, 2001.

LEÓN, Luis de: La perfecta casada, Javier San José Lera (ed.), Madrid, EspasaCalpe, 1992.

LOPE, Monique de: «L'églogue et la cour. Essai d'analyse des rapports de l'écriture théâtrale et de la fête chez Juan del Encina», en La fête et l'écriture: théâtre de cour, cour-théâtre en Espagne et en Italie, 1450-1530, Aix-en-Provence, Université de Provence, 1987, pp. 133-149.

LÓPEZ ESTRADA, Francisco: Los libros de pastores en la literatura española, Madrid, Gredos, 1974.

LÓPEZ MORALES, Humberto: Tradición y creación en los orígenes del teatro castellano, Madrid, Alcalá, 1968.

MARINIS, Marco de: «Lo spettacolo come testo (I)», Versus, 21 (1978), pp. 66-104. : «Lo spettacolo come testo (II)», Versus, 22 (1979), pp. 3-31.

PAVIS, Patrice: Diccionario del teatro: dramaturgia, estética, semiología, Barcelona, Paidós, 1983. 
PROFETI, Maria Grazia: «Luogo teatrale e scrittura: il teatro di Juan del Encina», Linguistica e Letteratura, 7 (1982), pp. 155-172 : «Comedias representadas-textos literarios: los problemas ecdóticos», en Teatro, historia y sociedad, Murcia / Ciudad Juárez, Universidad de Murcia / Universidad Autónoma de Ciudad Juárez, 1996, pp. 205-216.

PUERTO MORO, Laura: «Más sobre el humor en la tragicomedia. De personajes celestinescos y tipos cómicos tradicionales», eHumanista, 19 (2011), pp. 296316.

Real Academia Española: Diccionario de Autoridades, Madrid, Francisco del Hierro, 1726-1739. : Diccionario de la lengua española, Madrid, Espasa-Calpe, 2001.

REYES PEÑA, Mercedes de los (dir.): Cuadernos de Teatro Clásico. El vestuario en el teatro español del Siglo de Oro, 13-14 (2000).

SALOMON, Noël: Recherches sur le thème paysan dans la «comedia» au temps de Lope de Vega, Bordeaux, Institut d'Etudes Ibériques et Ibéro-américaines de l'Université de Bordeaux, 1965.

SAN JOSÉ LERA, Javier: «Teatro y texto en el primer renacimiento español. Del teatro al manuscrito e impreso», Studia Aurea, 7 (2013), pp. 303-338.

TEÓCRITO: Idilios, A. González Laso (ed.), Pamplona, Aguilar, 1963.

URreA, Pedro Manuel de: Cancionero, María Isabel Toro Pascua (ed.), Zaragoza, Prensas Universitarias de Zaragoza, 2012, vol. II y III.

VÁZQUEZ MELIO, María: «La configuración del personaje masculino en el teatro de Juan del Encina», Dicenda: Cuadernos de filología hispánica, 30 (2012), pp. 207-219. 